\title{
Association of KIR and TLR genes with Rheumatoid Arthritis
}

\author{
Pokhraj Guha ${ }^{1,2}$, Avishek Das ${ }^{1}$ and Tapas Kumar Chaudhuri ${ }^{1,3 *}$ \\ ${ }^{1}$ Department of Zoology, Cellular Immunology Laboratory, University of North Bengal, West Bengal, India \\ ${ }^{2}$ Department of Zoology, Garhbeta College, West Bengal, India \\ ${ }^{3}$ Department of Biotechnology, Brainware University, West Bengal, India
}

*Corresponding author: Tapas Kumar Chaudhuri, Cellular Immunology Laboratory, Department of Biotechnology, Brainware

University, India

\section{ARTICLE INFO}

Received: 㗀 July 15, 2020

Published: 幽 July 31, 2020

Citation: Pokhraj Guha, Avishek Das, Tapas Kumar Chaudhuri. Association of KIR and TLR genes with Rheumatoid Arthritis. Biomed J Sci \& Tech Res 29(2)-2020. BJSTR. MS.ID.004774.

Keywords: Rheumatoid Arthritis; Synovial Membrane; Autoimmune Disease

\section{ABSTRACT}

Rheumatoid arthritis (RA) is an autoimmune disease characterized by chronic inflammation of the synovial membrane of the joints caused by the infiltration of activated immune cells including CD4+ T cells, B cells, and antigen-presenting cells (APCs). It typically results in warm, swollen, and painful joints, thereby causing disabilities, deformities, premature deaths, and economic losses. Several estimations from hereditary studies suggest that genetic factors contribute $50 \%$ to the risk of developing RA. Indeed, the development of autoimmune diseases like rheumatoid arthritis (RA) depends significantly on the interaction of the genetic background with the surrounding environment. Killer Cell Immunoglobulin like Receptors (KIR) and Toll like Receptors (TLR) both play significant role in the pathogenesis of the disease. Some of the TLRs like TLR9 expressed on the synovial membrane tend to activate certain cytokines by interacting with the antigens present in the joints. TLR5 has also been documented to be associated with the progression of the disease. Associations of RA pathogenesis with TLRs depend on the environmental antigens that induce TLR expressions. It has also been documented that autoimmunity also activates the TLRs and induce disease progression. On the other hand, KIR receptors were also found to be associated with RA pathophysiology. Significant associations were reported for KIR2DL2, KIR2DS2, KIR2DS3, KIR2DS1 and KIR3DS1. Therefore, it will not be an overstatement to mention that gene-environment interactions play immense role in the pathophysiology of RA.

\section{Introduction}

\section{Markers of RA}

Various serological factors like CRP, anti-CCP, rheumatic factor (RF) are produced during the onset of the disease and are considered as clinical markers of the disease. C-Reactive proteins are produced in the hepatocytes of the RA patients triggered by certain cytokines like IL-6, TNF- $\alpha$ etc. [1]. The threshold concentration of this protein is $3.0 \mathrm{mg} / \mathrm{L}$. Rheumatoid factors are the autoantibodies that are produced against IgG subclasses and are found in the lymphoid follicles of synovial area [2]. Almost $70-80 \%$ of RA patients have been found to be positive for this marker. CD14-positive cells (monocytes) from the bone marrow stimulate RF-producing B cells [3]. IgM-RF is also one of the major clinical markers and can be detected in $60-80 \%$ of RA patients with a threshold level of $50 \mathrm{IU} / \mathrm{ml}$ [4]. The physiological role of RFs is to enhance the clearance of immune complex by increasing its avidity and size to help the B cells uptake the immune complex, and efficiently present to T cells. Anti-CCP is another well-known clinical marker of RA pathogenesis. It has comparably more specificity than RFs. Citrullinated peptides comprising non-standard amino acid are produced by post translation modification of arginine by peptidyl arginine deaminase (PADI) enzymes. The apoptotic cells also activate the enzyme. So, when apoptotic cells are not cleared properly, the level of this protein and enzyme are raised in the inflamed areas [5]. These peptides are mainly found in the form of filaggrin and cyclic citrullinated proteins. Autoantibodies 
are produced by the immune system in the synovial tissue against these altered peptides in case of RA and increase the severity of the disease. This prognostic marker in case of RA, especially during joint destruction scores $88 \%$ sensitivity and $98 \%$ specificity [6].

Presently, several genetic loci have been identified as diagnostic marker for RA in addition to the above-mentioned serological markers. Polymorphism of these genetic markers in different populations around the world predicted the susceptibility or resistance to the disease. Certain allelic variations or mutations may influence the prognosis of the disease in various populations. Recently two different markers have been identified which may influence the susceptibility or prognosis of Rheumatoid arthritis.

\section{Genetics of TLR with RA}

TLRs constitute one of the major markers of innate immunity that recognize various conserved antigens like LPS, bacterial flagellin, double stranded DNA, RNA. These markers are expressed on a variety of cell types such as NK cells, monocytes, epithelial cells etc. Cell surface TLRs like TLR1, 2, 4, 5 and 6 are known to interact with surface ligands of the pathogens. In contrast, intracellular TLRs like TLR3 and 7, 8 and 9 found on endosomal membranes, must have their ligands taken up inside the endosome in order to initiate downstream signaling pathways [7]. Binding of the TLRs with its corresponding ligands, result in the activation of either the MyD88-dependent or the MyD88-independent pathways. The MyD88-dependent pathway leads to the activation of NF- $\kappa$ B and promotes expression of cytokine genes [7].

TLR2 and TLR4 are primarily expressed in the blood monocytes of RA patients. Expressions of TLRs can also be found in the synovial tissue [7,8]. Endogenous TLR ligands in synovial tissue of RA patients include fibrinogen, heat shock protein 60 and 70 and fibronectin. These ligands activate certain TLRs in the synovial tissue and induce the production of various cytokines. A plethora of researches are being conducted throughout the World to explore the association of TLR with RA. Non-missense single nucleotide polymorphism in TLR4 was identified to be one of the risk factors for the development of RA in Chinese Han population [9], although several other studies have reported the lack of such associations [10]. Cytokines such as TNF, IFN- y, IL-6 also regulates the expression of TLRs in the synovial fluid in case of RA pathogenesis [11,12]. Chamberlain, et al. 2012 reported strong correlation of TLR5 and TNF- $\alpha$ with RA progression [13]. TLR5 has been postulated to be a TNF responsive gene and it is possibly linked to RA progression through induction of angiogenesis [13]. Transmission disequilibrium test conducted on the French families revealed no association of the major RA related TLRs (TLR1, 2, 6 and 9) with RA $[14,15]$.

\section{Genetics of KIR with RA}

The genetic heterogeneity of Killer cell immunoglobulin like receptors (KIR) has become an interesting topic for exploration by modern researchers since it helps to trace the association of KIR genes with the disease susceptibilities across different populations around the World. The KIR gene cluster spans about $150 \mathrm{~kb}$ in the LRC complex on chromosome 19q 13.4 [16]. KIR genotypes are not only characterized by variability in gene content but also demonstrate allelic variability [17]. Some of the KIR receptors are activating while others are inhibitory in nature. Different studies on KIR gene association with Rheumatoid arthritis endorse a linkage of this disease with KIR. KIR receptors are mainly involved in the immune function of NK cell membrane and CD28 null T-cells that are present in the synovial membrane [18] of the RA patients. NK cells present in the synovial membrane are very much sensitive to IL-12 and IL-15 that are present in inflamed joints. Activated NK cells secrete large amount of IFN-y [19] that directly activates macrophages.

RA patients having KIR2DL3 and lacking KIR2DS3 are generally diagnosed in early state. In addition, RA patients with extra-articular manifestations showed higher frequencies of KIR2DL2 and KIR2DS2 in comparison to controls [20,21]. KIR2DS2 is an activating receptor for intracellular signaling in NK cells. This receptor participates in $\mathrm{T}$ cell activation through ITAM molecules and thus increases IFN- $\gamma$ production $[22,23]$. It has also been postulated that a large amount of antibody was found in the RA patient for KIR2DL2 and must be blocked via signaling pathways for the disease [23]. Furthermore, it has also been found that the frequencies of KIR2DS1 and KIR3DS1 genes are lower in RA patients without bone erosions in comparison to healthy individuals $[20,21]$. It has been found that the frequency of KIR2DS4 was high among the Taiwan population and is a major risk factor for developing RA [22]. On the other hand, KIR2DL3 has been postulated to block the cytotoxic function and production of IFN- $\gamma$ which are important for RA auto reactivity [23-25], thereby playing a key role towards protection from this disease.

\section{Conclusion}

It can be inferred from the available evidences that KIR and TLR both play significant roles in RA pathogenesis. Genetic variations of both the markers may influence the susceptibility or resistant to the disease in various populations. Auto reactivity of the synovial cells and production of cytokines in RA pathogenesis has been reported to bear significant correlation with the activation of these markers. Autoimmune cells in the synovial tissue trigger both TLR and KIR signaling and influence cytokine production for RA progression. Therefore, it can be said that initial screening of both TLR and KIR must be carried out in various populations across the globe in order to reveal their associations with RA and devise better strategies to control the disease.

\section{References}

1. Kim, Bo Mi Kim KW, Moon HW, Lee SH, Kim HR (2015) Role of C-reactive protein in osteoclastogenesis in rheumatoid arthritis. Arthritis Res Ther 17: 41 .

2. Dissick A, Redman RS, Jones M, Rangan BV, Reimold A, et al. (2010) 
Association of periodontitis with rheumatoid arthritis: a pilot study. Periodontol 81: 223-230.

3. Hirohata S, Yanagida T, Itoh K, Nakamura H, Yoshino S, et al. (1996) Accelerated generation of CD14+ monocyte-lineage cells from the bone marrow of rheumatoid arthritis patients. Arthritis Rheum 39: 836-843.

4. Nell Duxneuner V, Machold K, Stamm T, Eberl G, Heinzl H, et al. (2010) Autoantibody profiling in patients with very early rheumatoid arthritis: a follow-up study. Ann Rheum Dis 69: 169-174.

5. Vossenaar ER, A van der Heijden, M A M van Mansum, C Dieteren, DJ de Rooij, et al. (2004) Expression and activity of citrullinating peptidylarginine deiminase enzymes in monocytes and macrophages. Ann Rheum Dis 63: 373-381.

6. Mimori T (2005) Clinical significance of anti- CCP antibodies in rheumatoid arthritis. Internal med 11: 1122-1126.

7. Huang QQ, Pope RM (2009) Role of Toll like receptors in rheumatoid arthritis. Curr Rheumatol Rep 11: 357-364.

8. Radstake TR, Roelofs MF, Jenniskens YM, Oppers Walgreen B, van Riel PL, Barrera P, et al. (2004) Expression of toll-like receptors 2 and 4 in rheumatoid synovial tissue and regulation by proinflammatory cytokines interleukin-12 and interleukin-18 via interferon-gamma. Arthritis Rheum 50: 3856-3865.

9. Yang H, Wei C, Li Q, Shou T, Yang Y, et al. (2013) Association of TLR4 gene non-missense single nucleotide polymorphisms with rheumatoid arthritis in Chinese Han population. Rheumatol Int 33: 1283-1288.

10. Xu WD, Liu SS, Pan HF, Ye DQ (2012) Lack of association of TLR4 polymorphisms with susceptibility to rheumatoid arthritis and ankylosing spondylitis: a meta-analysis. Joint Bone Spine 79: 566-569.

11. Radstake TR, Roelofs MF, Jenniskens YM, Oppers Walgreen B, Van Riel PL, et al. (2004) Expression of toll-like receptors 2 and 4 in rheumatoid synovial tissue and regulation by proinflammatory cytokines interleukin-12 and interleukin-18 via interferon gamma. Arthritis Rheum 50(12): 3856-3865.

12. Steiner G, Tohidast Akrad M, Witzmann G, Vesely M, Studnicka Benke A, et al. (1999) Cytokine production by synovial $T$ cells in rheumatoid arthritis. Rheumatology 38(3): 202-213.

13. Chamberlain ND, Volin Vila M, Arami OM, Volkov S (2012) Expression of TLR5 Strongly Correlates with Levels Of TNF-A and DAS28 In RA Monocytes and Ligation of TLR5 Induces Angiogenesis in RA. Arthritis Rheum 64: 2454.

14. Jaen O, Teixeira EP, Kirsten H, Ahnert P, Semerano L, et al. (2009)
ISSN: $2574-1241$

DOI: $10.26717 /$ BJSTR.2020.29.004774

Tapas Kumar Chaudhuri. Biomed J Sci \& Tech Res

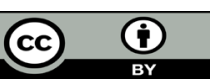

This work is licensed under Creative Commons Attribution 4.0 License

Submission Link: https://biomedres.us/submit-manuscript.php
No evidence of major effects in several Toll-like receptor gene polymorphisms in rheumatoid arthritis. Arthritis Res Ther 11: R5.

15. Orozco G, Morales S, González Gay MA, González Rugeles CI, Ramírez Quintero G, et al. (2005) Toll-like receptor 4 Asp299Gly polymorphism and rheumatoid arthritis: a replicative study in three different populations. Inmunología 24: 205-207.

16. Rajalingam R (2011) Human diversity of killer cell immunoglobulin like receptors and disease. The orean Journal of Hematology 46(4): 216-228.

17. Fasth AER (2010) Activating NK cell receptors co-stimulate $\mathrm{CD}_{4}+\mathrm{CD}_{28}-\mathrm{T}$ cells in patients with rheumatoid arthritis. European Journal of Immunology 40: 378-387.

18. Schreiber RD, Hicks LJ, Celada A, Buchmeier NA, Gray PW (1985) Monoclonal antibodies to murine interferon which differentially modulate macrophage activation and antiviral activity. J Immunol 134: 1609-1618.

19. Ramírez De los Santos S, Sánchez Hernández PE, Muñoz Valle JF, Palafox Sánchez CA, Rosales Rivera LY (2012) Associations of killer cell immunoglobulin- like receptor genes with rheumatoid arthritis. Dis Markers 33: 201-206.

20. Majorczyk E, Pawlik A, strokeuszczek WL, Nowak I, Winiewski A, et al. (2007) Associations of killer cell immunoglobulin-like receptor genes with complications of rheumatoid arthritis. Genes and Immunity 10 : 678-683.

21. Yen JH, Lin CH, Tsai WC, Wu CC, Ou TT (2006) Killer cell immunoglobulinlike receptor gene's repertoire in rheumatoid arthritis. Scand J Rheumatol 35(2): 124-127.

22. Yen JH, Brenda E Moore, Takako Nakajima, Dirk Scholl, Daniel J Schaid, et al. (2001) Major Histocompatibility Complex Class I-recognizing Receptors Are Disease Risk Genes in Rheumatoid Arthritis. Journal of Experimental Medicine 193(10): 1159-1167.

23. Matsui T (2001) Detection of Autoantibodies to Killer ImmunoglobulinLike Receptors Using Recombinant Fusion Proteins for Two Killer Immunoglobulin-Like Receptors in Patients with Systemic Autoimmune Diseases. Arthritis and Rheumatism 44: 384-388.

24. Rajagopalan S, Long EO (2005) Understanding how combinations of HLA and KIR genes influence disease. Journal Experimental Medicine 201(7): 1025-1029.

25. Williams AP, Andrew R Bateman, Salim I Khakoo (2005) Hanging in the balance: KIR and their role in disease. Molecular interventions 5(4): 226-240.

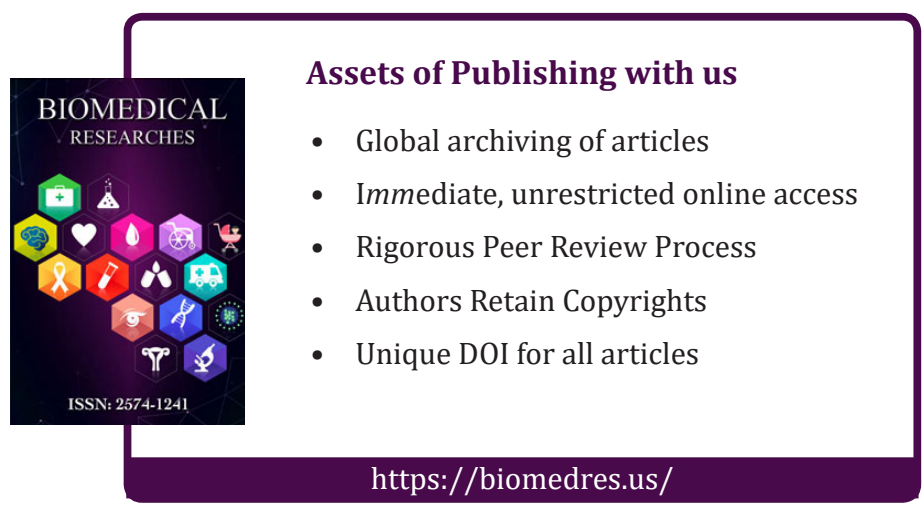

Copyright@ Tapas Kumar Chaudhuri | Biomed J Sci \& Tech Res | BJSTR. MS.ID.004774. 